\title{
Intelligent express delivery and transceiver system design based on NFC technology
}

\author{
Wei Wei $i^{1, a}$ \\ ${ }^{1}$ Wuhan City Vocational College, Wuhan, Hubei Province, China \\ a13317355@qq.com
}

Keywords: NFC technology, Intelligent, Express delivery, Sending and Receiving system

\begin{abstract}
With the Internet era, people willingness to accept the network shopping gradually improve, continuously improve logistics payment and other supporting services, various types of e-commerce platform have sprung up vigorously. Online shopping has become a way of life of people, which is associated with the express mail explosively increased. How to make logistics interrupt consumer's automation information become nowadays logistics must consider a problem. This paper will be collected in order to enhance express convenient degree, help property at the front desk and buyers to provide convenient, for the purpose of designing a intelligent since the transceiver system based on NFC, in order to improve the efficiency of the Courier and promote the development of express industry.
\end{abstract}

\section{Introduction}

The development of the Internet itself with the origin and development of logistics industry is inseparable. First of all, the Internet of things is based on the concept of the logistics industry. In the 20th century, the transport industry for effective transportation, loading and unloading, handling, storage of the goods need to produce the logistics industry, so there are logistics transportation. But with the development of world economy after World War II, logistics research also gradually by the scattered into the system, from disorder to order. Simply speaking, the development of modern logistics has experienced four stages: extensive logistics a systematic logistics, electronic logistics content instrumentation (smart) logistics [1]. Among them, the extensive logistics belongs to the stage of the prototype of the modern logistics, systematic logistics is a modern logistics development stage, and the electronic logistics is the mature stage of the modern logistics. And modern logistics in the future and hope is physical distribution, the intelligent logistics. With the support of the Internet of things technology, modern logistics are facing a sea change [1]. The following simple review of the emergence and development of modern logistics, and introduces the characteristics of the modern e-logistics. In addition, through three specific systems development and trend of intelligent logistics is discussed, and finally discusses intelligent logistics problems and challenges, and the Internet of things will guide the future direction of logistics.

\section{The development of the logistics delivery}

Extensive logistics. The golden age of extensive logistics is $50 \sim 70 \mathrm{~s}$ of the 20th century. After the Second World War, rapid recovery of the world economy, represented by the developed capitalist countries entered into a golden period of economic development. Manufacturing as the core of the economic development model brings to the western developed capitalist countries such as wealth, stimulate consumption growth on a massive scale [1]. A large number of productions, a large number of consumption become the sign of The Times. As a large number of products into the market, large department stores and supermarkets have mushroomed in general, such as Carrefour (founded in 1959) and Wal-mart (founded in 1962) [2]. In the early stage of the mass production and consumption due to the rapid economic growth, market demand, companies focus on the production, the circulation of logistics in the field of awareness is not high, is generally believed that maximize production will lead to the profit maximization, thus causing a large number of inventory. At the same time, the enterprise logistics activities, lack the necessary coordination of all departments. For 
example, the number of sales department only responsible for sales and inventory, transport part is responsible for the management of goods transport, decentralized management of logistics cost is high, low efficiency [2]. During this period, professional logistics enterprises are very few, most enterprises are sui generis, has no sense of industry collaboration and large logistics.

Systematic logistics. Systematic logistics benefit from the enterprise to the recognition of the importance of logistics industry, as well as the emergence of new technology and new models. During this period, the enterprise has taken the logistics as an integrated science, system engineering, operations research, market experts, municipal engineering, accounting and other disciplines begin to pay close attention to in the field of logistics and try to use their knowledge to study the law of logistics [2]. At the same time, the enterprise the management decision-making and development strategy has also begun to pay attention to the costs and benefits of logistics. Different from extensive logistics simply raising mode of production, logistics industry attention during this period inventory reduction to reduce operating costs, and introduces the concept of total logistics cost. The application of new logistics technology also caters to the trend, according to the facts when production system (Just In Time, JIT) and container transport, etc. In addition, the emergence of the emerging logistics business also enriches the service mode of logistics industry. Air express service, for example, in the early $70 \mathrm{~s}$, the founder of FedEx Fred Smith began using in 9731973 small aircraft air express business [2]. These new ideas, technology, service as the opportunity of logistics industry transformation and power. When it is worth mentioning that although the information technology revolution is still in its infancy, but in the logistics industry has already started to shine the spark of information technology, computer aided management, simulation, linear programming technique to use in the logistics system.

E-logistics. A typical example of using the barcode for e-logistics is united parcel service (UPS), the use of bar code. UPS in Louisville, Kentucky in the United States has a large aviation logistics transit center "world port", UPS in the "port of the world" to use electronic label the equipment improve the processing speed of the system, the benefit is obvious. "Port of the world", operating area of 400000 square meters, the size of 80 football fields, with 44 terminal near flight reservation, 17 of which have more than 000 conveyor belt, the goods is the average speed of $5 \mathrm{~m} / \mathrm{s}$. And the center business also amazing, an average of more than one million a day, during peak business day can reach 2. 5 Million Pieces. , a large number of high-speed mobile goods in crisscrossed the conveyor belt to do a few kilometers long interpenetrate and not the slightest error, with bar code label on the computer system for high precision control [2]. According to statistics, a Courier within 10 min can be transported to the target package box, and then was quickly sent to the cargo aircraft parked outside. It should be pointed out that, UPS not simply use a d barcodes, also use called Maxi code two-dimensional bar code system. This QR code an inch square, can store 93 bytes of data, include each item with standard delivery.

\section{NFC transceiver system design}

From the middle of the 20th century electronic technology, people have been pursuing the use of this technology to achieve faster, more convenient communication. Telegraph, telephone, fax, have been widely applied to the business, they initially in order to assist paper mainly trade measures; a large number of commercial activities need to pass the paper document to complete. The emergence of computer and network are real business into the digital era.

NFC technology principle. Near Field Communication namely close range wireless Communication technology; it is a short high frequency wireless Communication technology [3]. To allow electronic devices for non-contact point-to-point data transmits between exchange data. NFC based on radio frequency identification (RFID) technique. Require physical contact or is very close to the situation of (less than $10 \mathrm{~cm}$ ), thus obtain security.

NFC works is that the reader (which has the function of NFC device) sine wave radio frequency (RF), pass energy labels, and then read the data from the tag. NFC starts, sustainable production center frequency of $13.56 \mathrm{MHz}$ sine wave signal, if one of the tabs in the sine wave produced by the magnetic field perturbation range, within the scope of perturbation of magnetic field, the label will be 
obtained by perturbation of magnetic field energy, to produce the sine wave frequency or change the frequency properties of the wave, the reader to detect the change, will be able to judge the near the label. RFID in very close distance of communication is often referred to as close to matching system, nearly matching system scope is usually less than $10 \mathrm{~cm}$, which means that the label must be near the reader or installed on the reader [3]. Came close enough to the benefit is that the battery label field can be made a lot of energy, this energy is sufficient to support tag communication, without the need for the built-in power supply, nearly matching system is also conducive to the occasion of highly confidential [4]. Figure 1 illustrates the fro signal which has the function of NFC device how to produce, the tag antenna, how to obtain energy and process and equipment of the communication.

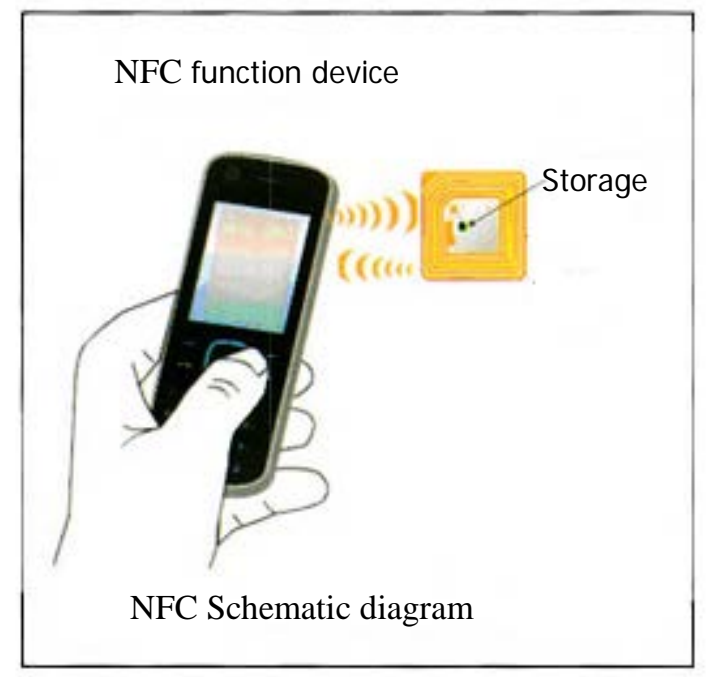

Fig.1 NFC Schematic diagram

System capabilities overview. Delivery person with each support NFC smart phones, smart phones are installed on the NFC intelligent inspection to the client [4]. On each tour more location or inspection equipment (such as transformer, tower, base station, fire hydrants, etc. ), placed for NFC tags. Inspection personnel in accordance with the inspection route setting, which in turn to each location for inspection, and according to the need to fill in the contents of the inspection.

About the data upload, the system provides two solutions:

1) The power system security requirements such as high places: the scheme of WIFI inspection record was on the phone, in the center set up WIFI routers, timing data uploaded to the platform.

2) The other place directly by using $3 \mathrm{~g}$ or $4 \mathrm{~g}$ technology, real-time upload.

Overall system design. This system is based on NFC and operator network, USES the open architecture design and function of modular design principles, to provide the open interface protocols, NFC implementation set data acquisition, express content, upload data real-time, record management system, fault analysis is one of the intelligent delivery system, the network topology is shown as Fig. 2.

NFC intelligent delivery system by the NFC tags, data acquisition subsystem and the center of the server subsystem network topology are [5]:

1) NFC tags: different equipment and place USES different kinds of labels, to ensure the reliable use of the label.

2) The data acquisition subsystem, data acquisition subsystem by Smartphone with (NFC) and NFC express of the client. System personnel mobile phone number for the account, login system, can read NFC tags. When after delivery person records the express content click "submit" button (if it is a security guard patrolling is not required) to the delivery point express the content of real-time database server via 3G/4G networks. A Courier delivery point is accomplished; express the client will be prompted to enter the next express delivery point, interface as shown in the figure below.

3) The center server subsystem consists of communication server, database server and a WEB server, realize the data receiving, storage, analysis, and user management, statement analysis, and other functions. Central server subsystem 


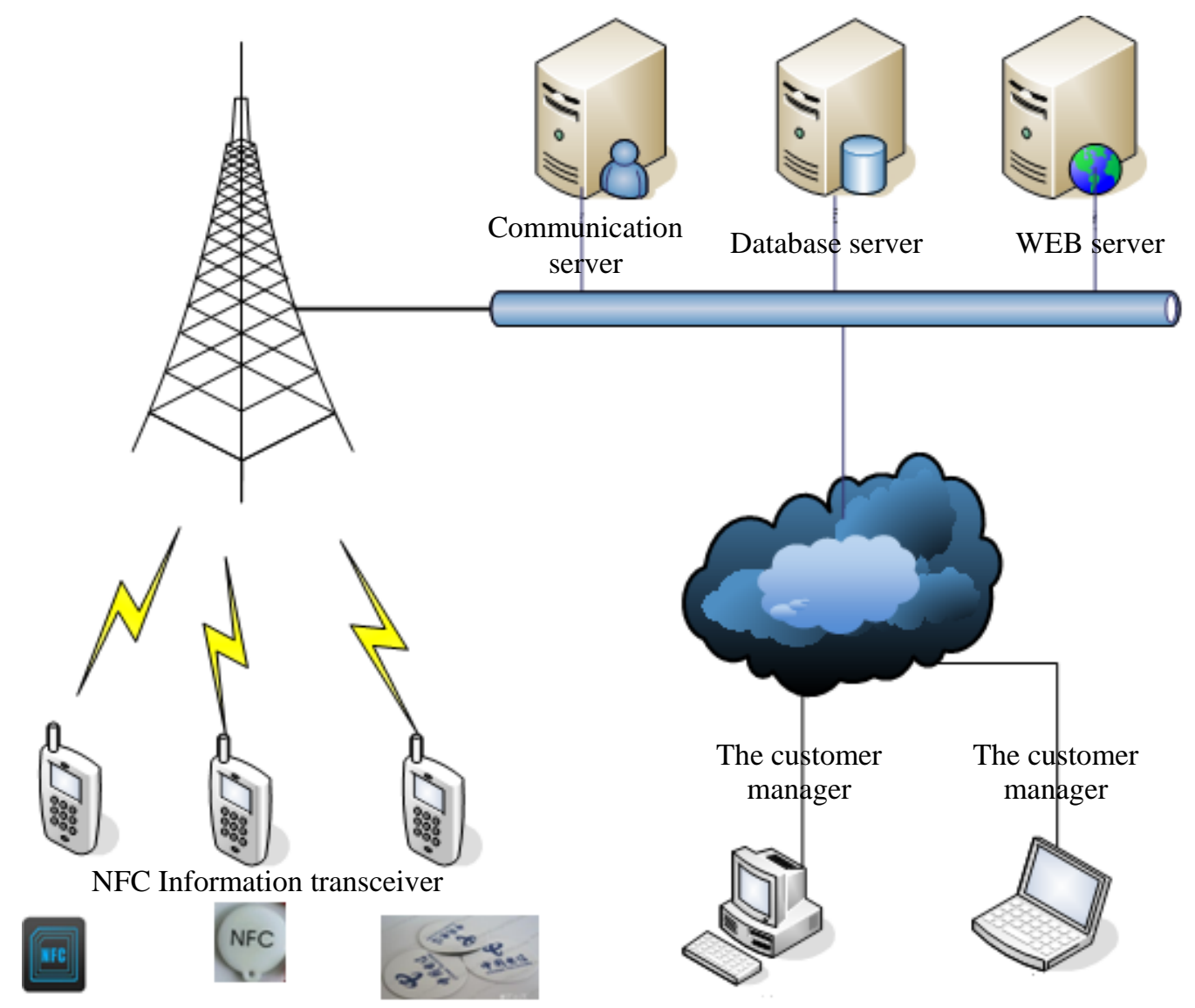

Fig. 2 Network topology of NFC expresses system

Data acquisition subsystem function. 1) NFC read function: delivery person USES the mobile phone number for the account, login system, directly read NFC tags. 2) Equipment delivery record function: can delivery person according to different requirements, fill in the equipment situation, whether the fault, fault content, etc., uploaded to the center. 3) Delivery prompt function: Tour prompt functions by establishing express route table, implementation of the new work have the effect of a prompt, check and supervision. Patrol alerts, and inspects the equipment to each need to express and patrol route are carried on the detailed annotation, delivery personnel can according to the prompt delivery work done in the shortest delivery route. Patrol prompt function and database server for real-time communications, real-time express route table, and can real-time reflect delivery point corresponding to the equipment working condition [6].

Equipment working status can be divided into the following kinds:

1) When the delivery point display is yellow, indicates that the delivery point is not express;

2) When the delivery point display for the green, shows that the express delivery point has been delivery and the delivery point of the equipment working state is normal;

3) When the delivery point displayed as red, shows that the express delivery point has been delivery, but the delivery point corresponds to the content of the equipment working status is not normal, and then there will be at the bottom of the patrol prompt system prompt. Which are shown as delivery point item which is not normal? The personnel on duty can accord the prompt, to the corresponding fault timely processing equipment [6]. In this way, can appear anomaly equipment, timely detection, timely processing, to ensure the safe and stable operation of the equipment. Patrol tips are offered the job of delivery cycle to set up and prompt system, patrol personnel can set according to the need to express delivery cycle, such delivery prompt automatic detection system for express delivery time, time for voice or alarm prompt.

Central server subsystem. Central Server subsystem adopts B/S structure, on NFC platform for development, it contains the corresponding communication software, management software and background management database (database development using SQL Server 2000). The background 
of management system is configuration in the application management server. The system can realize the centralized management of the patrol departments including Courier personnel, personnel authority distribution, delivery point increase or decrease setting content setting, express delivery, express delivery record query, and other functions. Users can access the Web site through the Internet, the client can remote implementation to the operation of the background management system. In order to improve the security of the system in operation, the user must pass the user identity. Brief introduction of system function as follows [7]: 1) according to the specified conditions, locations, divisions, the results, the date and time, etc. 2) according to the specified conditions, location, frequency, and the results, the date and time, etc. ) to print the related data statistics; For one or all of the Courier staff leak situation query, the summary record statistics report, print the leak. 3) for jobs, shift, frequency, time, personnel, and so on and so forth, such as: modify, add, delete, etc. , permissions and management. 4) the NFC tag number, location, time, etc. 5) record management, express delivery report. 6) Fault analysis function. 7) Provide MIS/OA system interface.

\section{Summary}

With the great development of electronic commerce, logistics, express delivery industry has entered the boom, because of the Internet of things and NFC technology in modern logistics industry, the application of intelligent express ark is in view of the electronic commerce and express delivery industry to develop a set of quick self-service system, realize the quick delivery service from a single dispersed to focus on the transition of the delivery, can effectively solve the electronic commerce and the express industry in the last 100 meters distribution and relevant problems, and can save the final 100 meters a lot of manpower material resources, gradually implement the artificial collecting goods into the form of automation, send and receive express packages automatic and remote query and control, NFC is the effective way to solve the bottleneck of e-commerce development.

\section{Acknowledgement}

Fund project: Wuhan city Colleges and universities production research project of 2016 Wuhan Education Bureau. (Project ID: CXY201638).

\section{References}

[1] D.Y. Din, The things of internet with smart logistics, China logistics and purchasing, 2010, vol.8, pp.34-36.

[2] K.Ch.Ke, The current situation of the modern logistics industry development in China, The countermeasures of modern economy, 2008, vol.9, pp.80-82.

[3] Zh.Sh. Liu, Discusses some issues of logistics system, Railway procurement and logistics, 2007, vol.6, pp. 23 and 24.

[4] M.T. Zhou, Development status and trend of intelligent logistics system at home and abroad, The railway procurement and logistics, 2007, vol.2, pp.23-27.

[5] Y.M. Mao, The development trend of intelligent logistics system, Logistics and purchasing in China, 2014, vol.6, pp.12-16.

[6] Y.Y. Chang, The existing problems in the development of modern logistics industry in our country and countermeasures, Modern management science, 2008, vol.1, pp.55-60.

[7] P.F. Xu, The Internet things of intelligent logistics industry development, Modern management science, 2008, vol.1, pp.45-48. 